\title{
Análise do conforto termo fisiológico e da resistência à tração em tecido tramado com algodão reciclado e filamentos obtidos da reciclagem de resíduos pós-consumo de garrafas pet
}

\author{
Analysis of the thermophysiological comfort and \\ tensile strength in fabric woven with recycled cotton \\ and filaments obtained from post-consumer \\ waste pet bottle recycling
}

Juliana Lunkes Schmitt ${ }^{1}$, Luis Fernando Folle ${ }^{1}$

\author{
${ }^{1}$ Mestre em Design Uniritter, UniRitter, Porto Alegre, RS, Brasil. \\ e-mail: schmitt.julianalunkes@gmail.com,e-mail: folle.luis@gmail.com
}

\begin{abstract}
RESUMO
O Brasil é um importante produtor de têxteis e confecção. Possui o quarto maior parque fabril e é o quinto maior produtor de têxteis do mundo. Em contrapartida, também é responsável pela produção de toneladas de resíduos sólidos que, na sua maioria, é descartada em aterros sanitários, aterros controlados e lixões. Parte dos resíduos têxteis descartados é encaminhado para reciclagem, gerando diferentes tipos de produtos finais, inclusive novos tecidos. Os tecidos reciclados são produzidos no Brasil há mais de duas décadas, porém, somente nos últimos anos que esta matéria prima está sendo empregada na produção de vestuário, calçados e acessórios. Este trabalho tem por objetivo analisar a estrutura de um tecido produzido a partir de fios obtidos da reciclagem de algodão e garrafas PET (polietileno tereftalato) e avaliar seu desempenho em relação ao conforto termo fisiológico e à resistência à tração, quando comparado a um tecido produzido a partir de fibras virgens. A metodologia utilizada partiu da seleção de um tipo de tecido que apresentasse características similares relacionadas à composição, ligamento e à gramatura, sendo ele constituído de filamentos reciclados e $100 \%$ virgens. O tecido selecionado para a pesquisa foi do tipo sarja $3 \times 1$ com composição mista de algodão e poliéster. Foram realizados ensaios de tração, permeabilidade ao vapor de água, condutividade térmica, titulação e micrografias. Os resultados obtidos indicam que o tecido reciclado utilizado nesta pesquisa é viável para a produção de roupas para as estações outono/inverno, e para desenvolvimento de roupas cujas modelagens apresentem folga de vestibilidade.
\end{abstract}

Palavras-chave: Tecidos reciclados. Algodão. PET. Resistência à tração. Conforto termo fisiológico.

\begin{abstract}
Brazil is an important producer of textiles and clothing. It owns the fourth largest manufacturing park and is the fifth largest producer of textiles in the world. On the other hand, it is also responsible for the production of tons of solid waste, which is mostly discarded in landfills, controlled landfills and dumps. Part of the discarded textile waste is sent for recycling, generating different types of final products, including new fabrics. Recycled fabrics have been produced in Brazil for more than two decades, but only in recent years has this raw material been used in the production of clothing, footwear and accessories. The objective of this work is to analyze the structure of a fabric produced from yarn obtained from the recycling of cotton and PET bottles (polyethylene terephthalate) and to evaluate its performance in relation to the thermophysiological comfort and the tensile strength when compared to a fabric produced at from virgin fibers. The methodology used was based on the selection of a type of tissue that presented similar characteristics related to the composition, ligament and weight, being composed of recycled filaments and $100 \%$ virgin. The fabric selected for the research was $3 \times 1$ twill type with mixed composition of cotton and polyester. Traction tests, water vapor permeability, thermal conductivity, titration and micrographs were performed. The results indicate that the recycled fabric used in this research is feasible for the production of clothes for the autumn / winter seasons, and for the development of clothes whose models have vestigial playability.
\end{abstract}


Keywords: Recycled fabrics. Cotton. PET. Tensile strength. Thermophysiological.

\section{INTRODUÇÃO}

A principal matéria prima dos designers de moda é o tecido, e através dele suas ideias são transformadas em produtos de vestuário [1]. É relevante para o designer de moda conhecer os tecidos e suas propriedades, uma vez que eles se relacionam com a estética visual, a ergonomia, a temperatura corporal e consequentemente, a percepção geral de conforto pelo usuário.

O Brasil é um importante produtor de têxteis e confecções a nível mundial, sendo o único país do Ocidente que atua em todas as etapas da cadeia têxtil, desde a produção de fibras, passando pela fiação, tecelagem, beneficiamento, confecção e varejo. Responsável pela produção anual de 5,9 bilhões de peças (Referese a diversos tipos de produtos: vestuário, meias, acessórios, cama, mesa e banho) e um faturamento de US\$ 45 bilhões, é o quinto maior produtor têxtil do mundo e o quarto maior parque produtivo de confecção [2].

Juntamente com esses números positivos, que apontam o desenvolvimento industrial e econômico brasileiro, é imprescindível salientar que a cadeia têxtil e confeccionista é uma das principais responsáveis por problemas ambientais, tais como a contaminação do solo, da água e do ar [3]. Segundo CARVALHAL [4], a indústria da moda contribuiu de modo significativo para o atual desequilíbrio planetário, sendo a segunda atividade mais poluidora do século XX e a segunda que mais consumiu recursos naturais, depois da agricultura.

O ritmo acelerado da produção de roupas, para assegurar o abastecimento dos grandes varejos com lançamentos semanais, contribui para o aumento na geração de resíduos sólidos oriundos dos processos industriais e pós-consumo. Isto ocorre porque o ciclo de vida (conjunto das etapas da vida de um produto do berço ao túmulo [3]) dos produtos é muito menor. Na busca de alternativas que possam contribuir com a preservação ambiental, um crescente número de empresas tem buscado na reciclagem uma alternativa sustentável diante desse cenário. Os tecidos reciclados, produzidos a partir de fibras recicladas de algodão e resíduos pósconsumo de garrafas PET apresentam-se como uma opção ao uso de tecidos tramados a partir de fibras virgens.

Segundo BERLIM [3], o algodão concorre com o poliéster como a fibra de maior consumo no planeta. A produção de algodão é considerada uma das mais letais e sujas do mundo. Os pesticidas usados nas plantações de algodão são responsáveis pela morte de milhares de agricultores, além de contaminar o solo, a água e o ar [5]. Da mesma forma, os impactos ambientais decorrentes do uso do poliéster são consideráveis. A indústria do plástico é um dos setores da economia que mais se desenvolveu nos últimos anos, com destaque para a produção de embalagens. Um dos usos mais populares do poliéster se apresenta na forma de embalagens plásticas para bebidas. O poliéster é um material extraído do petróleo, recurso natural fóssil não renovável, e seu tempo de decomposição no meio ambiente demora em média cem anos, contribuindo para os problemas ambientais [3].

A reciclagem de resíduos industriais têxteis e resíduos pós consumo de garrafas PET permitiria contribuir para a redução dos impactos ambientais, evitando a extração de matéria prima virgem da natureza e contribuindo para a geração de novos produtos, contribuições relevantes que justificam esta pesquisa.

No entanto, uma pergunta surge a partir da reciclagem desses materiais para a confecção de tecidos: os tecidos tramados a partir de fibras recicladas oferecem o mesmo conforto termofisiológico e resistência que os tecidos tramados a partir de fibras virgens?

Para esta pesquisa, usou-se a denominação de Tecido Reciclado (TR) para os tecidos tramados a partir de fios oriundos da reciclagem de algodão e PET e Tecido Não-Reciclado (TNR) para o tecido tramado a partir de fibras virgens.

\section{MATERIAIS E MÉTODOS}

O tecido selecionado para esta pesquisa foi o jeans e sua escolha justifica-se pelo fato deste ser um dos tecidos mais usados no mundo. Pesquisa realizada pela Lycra ${ }^{\circledR}$ em cinco países (Brasil, Alemanha, China, Estados Unidos e Espanha), revelou que o jeans é peça chave no guarda roupa feminino. Segundo o levantamento geral, cada mulher possui em média oito peças jeans, sendo que no Brasil essa média aumenta para 9,3 peças por pessoa [2].

O jeans possui estrutura sarja. Entende-se por estrutura, a organização que os fios de trama e urdume apresentam de modo a formar o tecido. A estrutura sarja (figura 1) caracteriza-se pela sua linha em diagonal e pelo seu padrão de repetição mínimo de três fios de urdume e três fios de trama. A estrutura em diagonal con- 
SCHMITT , J.L.; FOLLE, L.F.. revista Matéria, v.26, n.1, 2020.

fere ao tecido uma maior maleabilidade e resistência.

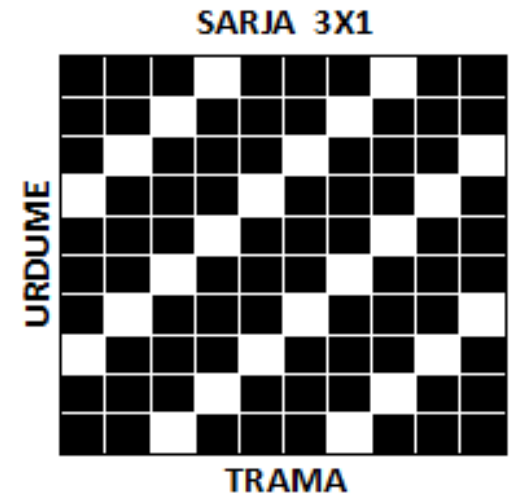

Figura 1: Ligamento Sarja 3x1 Pesada.

$\mathrm{Na}$ representação quadriculada, os quadrados preenchidos representam que o fio de urdume passam por cima do fio da trama (sem preenchimento) [6]. Os tecidos, na sua grande maioria, possuem duas faces distintas, que indicam o lado direito e o lado avesso do tecido. O lado direito do tecido possui mais brilho, toque ou aspecto mais suavizados e definidos, podendo apresentar efeitos de relevo ou estrias mais nítidas que o avesso. Já o avesso do tecido caracteriza-se por ser mais fosco, com toque e aspectos mais rústicos e superfície mais lisa do que o lado direito [7].

Para que os dados obtidos através dos ensaios apresentassem valores que pudessem ser comparados, os tecidos precisavam apresentar similaridade em relação a sua composição, estrutura e gramatura. O tecido reciclado utilizado para esta pesquisa chama-se Star e foi adquirido da empresa Ecosimple Indústria e Comércio de Tecidos Sustentáveis. É um tecido misto composto por 59\% CO reciclado e $41 \%$ PET reciclado. Possui ligamento sarja 3x1, estrutura pesada e gramatura $243 \mathrm{~g} / \mathrm{m}^{2}$.

O TNR foi fornecido pela empresa Tecelagem Santanense. Seu nome comercial é UniOffice, sendo um tecido frequentemente utilizado para a produção de roupas profissionais. É um tecido misto de composição $65 \%$ algodão e $35 \%$ poliéster, ligamento sarja $3 \times 1$, estrutura pesada e gramatura $266 \mathrm{~g} / \mathrm{m}^{2}$.

\subsection{Determinação do título de fios}

Para se obter o título de um fio são necessários dispositivos que permitam medir com precisão o comprimento e peso das amostras. Os métodos utilizados precisam estar adaptados para o formato que o fio se apresenta, seja ele em bobina ou como fios de trama e urdume desfiados do tecido [8].

O ensaio de determinação do título de fios segue a norma NBR 13214 [9] que prescreve o método para determinação do título de fios em materiais têxteis, sem a extração de produtos e em equilíbrio com a atmosfera padrão de ensaios. É importante consultar as normas NBR 8427 [10] e NBR 8428 [11], pois fornecem informações sobre a aplicação do sistema tex para expressar títulos e como condicionar os materiais têxteis para os ensaios. Para os efeitos desta Norma são adotadas as seguintes definições.

- Título: no sistema direto, exprime a massa por unidade de comprimento (densidade linear) de um fio;

- Unidade: Tex exprime a massa em gramas de 1.000 metros de fio.

Foram retiradas por desfiamento, amostras de fios no sentido do urdume e da trama do TR e TNR. Foram utilizadas amostras de fios totalizando o comprimento linear de 1 metro,

Os fios foram enrolados no formato de meada e foram pesados em uma balança analítica de precisão da marca Bel Engineering, com resolução mínima de 0,0001 gramas e máxima de 210 gramas.

\subsection{Determinação da gramatura de superfície têxtil}

O ensaio de gramatura, cuja norma regulamentadora é a NBR 10591 [12], teve como objetivo verificar a massa por unidade de área. Este ensaio possibilita aferir a gramatura expressa nas amostras fornecidas pelas tecelagens.

O equipamento utilizado foi uma balança analítica de precisão da marca Bel Engineering, com resolu- 
SCHMITT , J.L.; FOLLE, L.F.. revista Matéria, v.26, n.1, 2020.

ção mínima de 0,0001 gramas e máxima de 210 gramas. Para a realização do ensaio, foram cortados cinco corpos de prova de cada tecido, com dimensões de $5 \mathrm{~cm}^{2}$, retiradas de lugares isentos de defeitos, com fios de trama e de urdume distintos. A norma da ABNT sugere que os corpos de prova tenham $15 \mathrm{~cm}^{2}$, sendo que outras dimensões podem ser adotadas, desde que descritas no relatório como desvio da norma.

\subsection{Microscopia óptica}

Para a realização das imagens foram utilizadas amostras com dimensões $10 \mathrm{~cm}^{2}$ do TR e do TNR. Foram feitas imagens com ampliação de 36,3 e 104,8 vezes. O equipamento utilizado foi da marca Class modelo 3020VM e o software VMS 3D.

\subsection{Determinação da permeabilidade ao vapor de água}

Este ensaio foi realizado no Instituto Brasileiro de Tecnologia do Couro, Calçados e Artefatos - IBTEC utilizando a norma NBR 12834 [13], que trata sobre a determinação da permeabilidade ao vapor de água como referência. $\mathrm{O}$ equipamento utilizado foi um permeabilímetro. Um corpo de prova com dimensões de $20 \mathrm{~cm}^{2}$ de cada um dos tecidos (TR e TNR) foram armazenados durante 24 horas em ambiente climatizado e ensaiados na temperatura e umidade relativa do ar do laboratório conforme exigência da NBR 10455 [14] (Temp. $23+-2^{\circ} \mathrm{C} /$ Umid. $50+-5 \%$ ). Os corpos de prova foram posicionados na boca de garrafas preenchidas pela metade com sílica-gel (dissecante sólido). Foram identificados nos corpos de prova o lado avesso do tecido que ficará em contato com a pele do usuário pois, para a realização do ensaio, coloca-se o avesso para o lado de fora da garrafa. Em seguida, foram colocadas as garrafas no suporte, onde ficaram expostas a uma forte corrente de ar, por um determinado período. O ar e o dissecante dentro do copo ficaram em movimento constante. A umidade que atravessou o corpo de prova foi absorvida pelo dissecante e determinada pela diferença de peso do copo entre o final e início do teste.

\subsection{Determinação da permeabilidade ao vapor de água}

Os ensaios de condutividade térmica foram realizados no laboratório do IPT, utilizando o aparelho Thermal Condutivity Analyzer da Marca C-Therm. Para este ensaio utilizou-se o método do equipamento TCi, em razão da ausência de uma norma específica para este fim.

$\mathrm{O}$ analisador de condutividade térmica da marca C-Therm utiliza um sensor de refletância de calor, unilateral, interfacial que aplica uma fonte de calor constante momentânea na amostra. Uma corrente elétrica é aplicada ao elemento de aquecimento do sensor, gerando uma pequena quantidade de calor.

Este calor resulta em aumento na temperatura na interface (entre o sensor e a amostra). Esse aumento de temperatura na interface induz uma mudança na queda de voltagem do elemento do sensor. A taxa de aumento de voltagem no sensor é utilizada para determinar as propriedades termo físicas da amostra. As propriedades termo físicas da amostra são inversamente proporcionais à taxa de aumento da voltagem do sensor. Quanto mais isolante térmico o material é, maior e mais íngreme é o aumento da voltagem. Os resultados são mostrados em um computador em tempo real [15].

\subsection{Determinação da resistência à tração}

O ensaio de tração utilizado nesta pesquisa, teve como suporte a norma da NBR 11912 [16]. Esta norma aborda os aspectos relativos à determinação da resistência à tração e alongamento de tecidos planos (tiras) em dinamômetro tipo CRT. O equipamento utilizado foi a máquina de ensaios universal da Marca EMIC, modelo DL 10000, com célula de carga de $500 \mathrm{Kg}$ e transdutor de deslocamento embutido. A distância entre as garras foi ajustada para $200 \mathrm{~mm}$ e a velocidade de deslocamento durante os testes de $300 \mathrm{~mm} / \mathrm{min}$.

Foram cortados cinco corpos de provas em cada um dos três sentidos dos tecidos (trama, urdume e viés). Cada unidade com dimensões de $300 \mathrm{~mm}$ de altura por $60 \mathrm{~mm}$ de largura, foi desfiada $5 \mathrm{~mm}$ no comprimento a partir da borda. O sentido do viés não está descrito na norma, porém entende-se que é importante para a pesquisa avaliar o desempenho também neste sentido do tecido.

As extremidades dos corpos de prova foram fixadas nas garras de fixação do dispositivo de testes, que alongou o corpo de provas em uma taxa constante, ao mesmo tempo que mediu de forma contínua a carga instantânea que foi aplicada e os alongamentos resultantes. Os resultados dos ensaios de tração foram registrados em tempo real em um computador através de gráficos, na forma força $(\mathrm{N})$ em função do alongamento (mm).

\section{RESULTADOS E DISCUSSÕES}


SCHMITT , J.L.; FOLLE, L.F.. revista Matéria, v.26, n.1, 2020.

Inicialmente, realizou-se uma avaliação a olho nu dos dois tecidos. O TR apresenta na sua superfície algumas fibras soltas com aspecto de pilling (pequenos acúmulos de tecido em forma arredondada), como pode-se observar na figura 2. Por sua vez, o TNR apresentou uma superfície lisa e homogênea, sem presença de pillings.
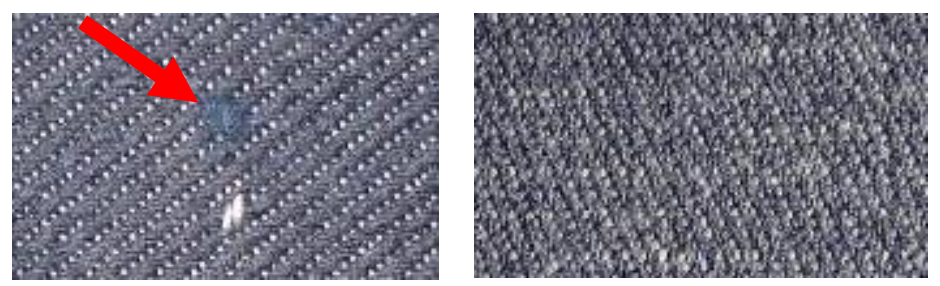

Figura 2: Superfícies dos tecidos. Esquerda: TR - Superfície com pilling. Direita: TNR - Superfície sem pilling.

Supõe-se que as fibras soltas presentes na superfície do TR, são resultado do encurtamento das fibras de algodão após o processo de reciclagem. Em relação à reciclagem dos resíduos de algodão, ZONATTI [17] esclarece que os tecidos que serão reciclados, são processados e retornam à condição de fibras que resultam num comprimento aproximadamente $20 \%$ menor que a fibra original virgem utilizada no primeiro processo de industrialização. Outra hipótese para a presença de pillings na superfície do TR atribui-se ao sistema de fiação à rotor, onde a fiação das fibras curtas obtém melhor performance. Este sistema possui uma maior produtividade, porém, produz fios mais grossos e com resistência inferior.

\subsection{Título do fio}

Devido à forma variada e irregularidade dos fios, o diâmetro não é o parâmetro mais adequado para medir a espessura [8]. O título de um fio expressa a relação entre sua massa e seu comprimento, ou sua massa linear. Para a presente pesquisa, utilizou-se o sistema de titulação direto, onde mede-se a massa em função do comprimento. Seu resultado é expresso utilizando a unidade de medida internacional TEX, definida como a massa em gramas contida em 1000 metros de fio.

Os corpos de prova retirados do tecido foram identificados, enrolados em formato de meada e pesados. A tabela 1 mostra estes resultados.

Tabela 1: Titulação dos fios obtidos no sistema direto.

\begin{tabular}{c|c}
\hline Tecido & Título \\
\hline TR trama $(\mathrm{COr})$ & $85,1 \mathrm{Tex}$ \\
\hline TR urdume $(\mathrm{PESr})$ & $16,7 \mathrm{Tex}$ \\
\hline TNR trama $(\mathrm{CO})$ & $68,1 \mathrm{Tex}$ \\
\hline
\end{tabular}

Em complemento à identificação do título dos fios, o número de filamentos por centímetro indica a densidade de fios. A tabela 2 mostra estes resultados.

Tabela 2: Densidade do tecido.

\begin{tabular}{c|c|c}
\hline Tecido & Fios urdume & Fios trama \\
\hline Reciclado & 21 fios & 28 fios \\
\hline Não reciclado & 44 fios & 20 fios \\
\hline
\end{tabular}

\subsection{Gramatura de superfície têxtil}

Como já citado anteriormente, para atingir os objetivos propostos pela pesquisa, os tecidos analisados precisavam apresentar estrutura, composição e gramaturas similares. Os tecidos fornecidos pelas empresas foram adquiridos através de seus representantes comerciais, baseado apenas nos dados fornecidos pelos mesmos, sem contato prévio com o tecido. 
SCHMITT , J.L.; FOLLE, L.F.. revista Matéria, v.26, n.1, 2020.

De posse dos tecidos, percebeu-se que o TR aparentava ser mais espesso e pesado que o TNR, fazendose necessária uma análise da gramatura dos tecidos. Após o corte dos corpos de prova, realizou-se a pesagem individual de cada uma das amostras. Os valores encontrados foram registrados na tabela 3:

Tabela 3: Peso dos tecidos.

\begin{tabular}{c|c|c}
\hline \multicolumn{3}{c}{ Massa (gramas) } \\
\hline Amostras & Reciclado & Não reciclado \\
\hline 1 & 0,627 & 0,68 \\
\hline 2 & 0,641 & 0,672 \\
\hline 3 & 0,618 & 0,663 \\
\hline 4 & 0,643 & 0,672 \\
\hline 5 & 0,621 & 0,67 \\
\hline Média & $\mathbf{0 , 6 3}$ & $\mathbf{0 , 6 7 1}$ \\
\hline
\end{tabular}

A média dos valores encontrados em gramas foram convertidos para $\mathrm{g} / \mathrm{m}^{2}$. Foi constatado que os dois tecidos apresentam diferenças pouco significativas em relação a gramatura descrita na etiqueta de identificação do produto, conforme é mostrado na tabela 4:

Tabela 4: Comparação entre as gramaturas medidas e dadas pelo fabricante.

\begin{tabular}{c|c|c}
\hline \multicolumn{3}{c}{ Gramatura $\left(\mathbf{g} / \mathbf{m}^{\mathbf{2}}\right)$} \\
\hline & Reciclado & Não reciclado \\
\hline Medido & 252 & 268 \\
\hline Etiqueta do Fabricante & 243 & 266 \\
\hline
\end{tabular}

Em relação ao aspecto dos tecidos e seu peso, é possível concluir que o TR apresenta maior volume e menor peso, enquanto o TNR possui aspecto leve, porém é mais pesado.

\subsection{Microscopia óptica}

A microscopia óptica fornece informações relevantes sobre a estrutura dos fios e dos tecidos. Para esta pesquisa foram realizadas imagens dos tecidos com ampliação de 36,3 vezes e imagens longitudinais dos fios com aumento de 104,8 vezes.

Percebe-se que o fio azul de CO reciclado é irregular e possui uma grande quantidade de fibrilas em seu contorno. Segundo ZONATTI [17], as fibrilas são os diversos fios mais finos soltos por entre o cabo. A presença de fibrilas no contorno do fio esclarece a presença de pillings na superfície do TR. Na Figura 3 é possível visualizar os fios de poliéster e algodão reciclado com aumento de 104,8 vezes. Os diversos filamentos que compõem o fio de PES reciclado apresentam-se na cor original, sem tingimento.

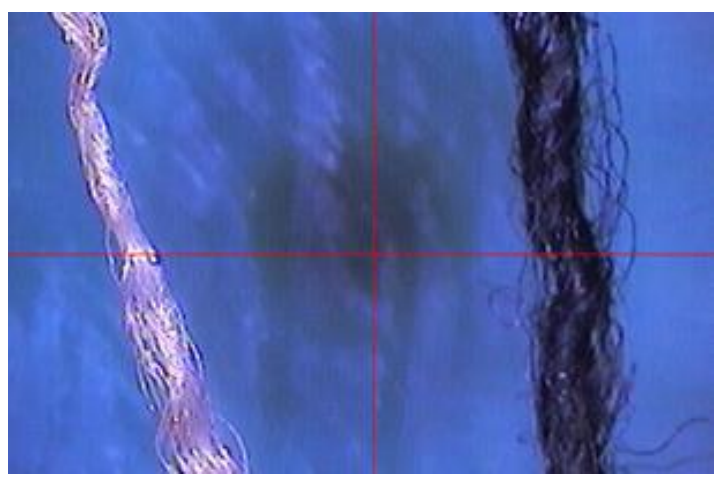

Figura 3: Micrografia ótica de fios do TR (ampliação de 104,8X).

Na Figura 4 percebe-se que o fio de CO do TNR é mais coeso e apresenta mais torções em comparação 
SCHMITT , J.L.; FOLLE, L.F.. revista Matéria, v.26, n.1, 2020.

ao fio de CO reciclado. Identifica-se também, que o fio de PES reciclado é composto por filamentos na cor original e tingidos de azul.

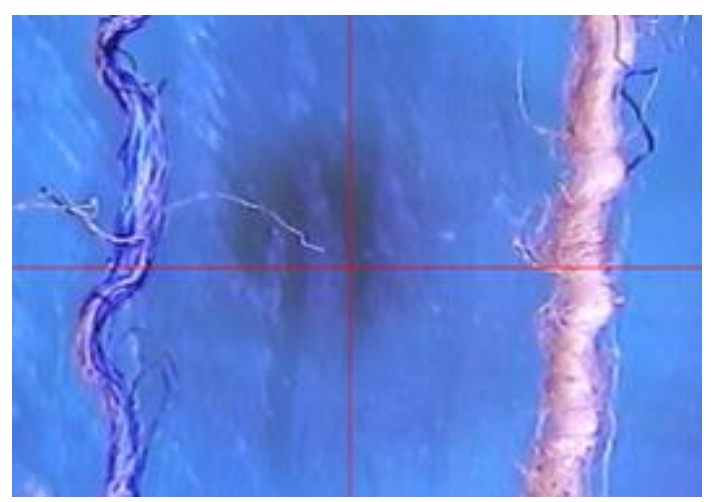

Figura 4: Micrografia ótica de fios do TNR (ampliação de 104,8X).

Também foram realizadas imagens do tecido com aumentos de 36,3 vezes para analisar sua estrutura. Percebe-se no TR quase não há espaços vazios entre os fios de trama e urdume (figura 5), diferentemente do TNR onde são verificados diversos espaços vazios (figura 6). As imagem da esquerda nas figura 6 foi captada com auxílio de uma luz superior ao tecido, e a imagem da direira, a luz estava posicionada na porção inferior ao tecido, permitindo visualizar pontos de luz (mostrados pela flecha fermelha) que representam os espaços vazios entre os fios.

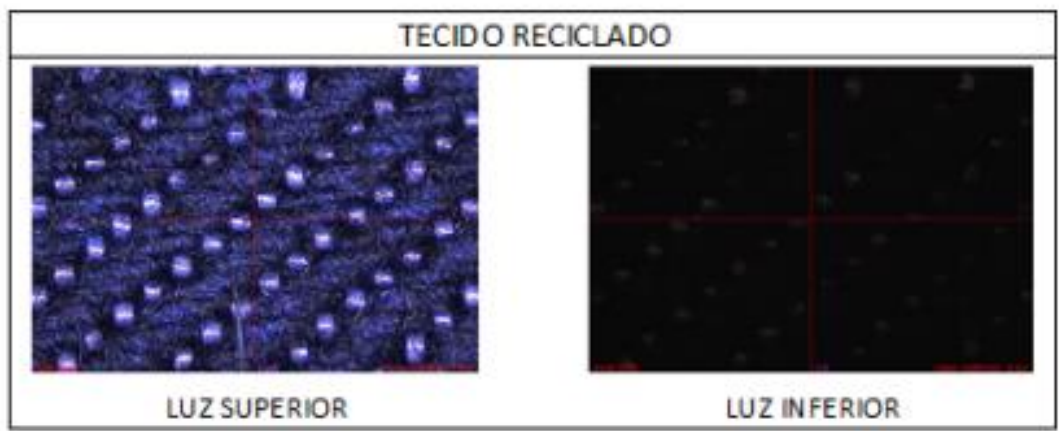

Figura 5: Espaços vazios entre fios no TR (ampliação de 36,3X).

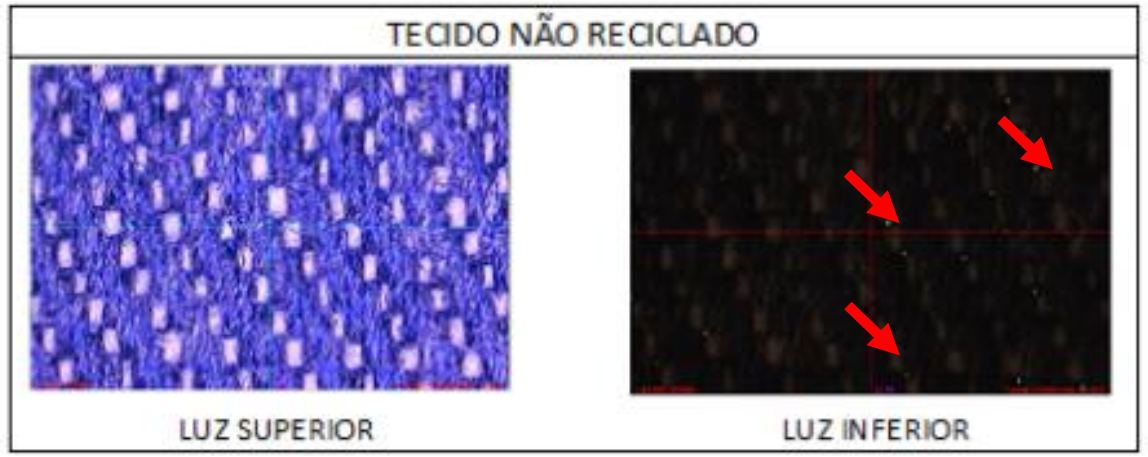

Figura 6: Espaços vazios entre fios no TNR (ampliação de 36,3X).

Os espaços vazios revelam indícios sobre o transporte de vapor de água por entre o substrato têxtil, porém, fez-se necessária a análise laboratorial sobre a permeabilidade ao pavor de água.

\subsection{Permeabilidade ao vapor de água}


SCHMITT , J.L.; FOLLE, L.F.. revista Matéria, v.26, n.1, 2020.

O transporte do vapor de água tem papel significativo na determinação do conforto térmico. É importante, para o balanço térmico corporal, que a umidade gerada pelo suor seja evaporada e não fique retida entre a pele e o artigo têxtil [18]. O ensaio de permeabilidade ao vapor de água consiste na passagem da água sob a forma de vapor pelo substrato têxtil [19].

O objetivo deste ensaio foi verificar a quantidade de vapor que ultrapassa os substratos têxteis e sua influência no conforto térmico. Foram realizadas três medições, em pontos diferentes dos corpos de provas, e seus valores foram registrados, conforme mostra a tabela 5 .

Tabela 5: Valores de permeabilidade ao vapor de água.

\begin{tabular}{c|c|c}
\hline & \multicolumn{2}{|c}{ Permeabilidade ao vapor de água $\mathbf{( m g / \mathbf { c m } ^ { 2 } . \mathbf { h } )}$} \\
\hline Amostras & Reciclado & Não reciclado \\
\hline 1 & 18,7 & 18,8 \\
\hline 2 & 19,1 & 20,6 \\
\hline 3 & 17,3 & 17,0 \\
\hline Média & $\mathbf{1 8 , 4}$ & $\mathbf{1 8 , 8}$ \\
\hline
\end{tabular}

Os valores médios de transmissão de vapor de água através dos tecidos foram semelhantes, porém, o TNR permitiu que uma quantidade maior de vapor de água ultrapassasse pelo substrato têxtil em relação ao TR. Tal resultado aponta que a quantidade de espações vazios interfere positivamente na evaporação do vapor corporal. Este dado aponta que o TNR poderá ser mais confortável que o TR em relação ao conforto térmico quando utilizado no verão, pois irá permitir maior transpasse do vapor para fora da roupa.

\subsection{Condutividade térmica}

O calor é uma forma de energia que pode ser transferida de um sistema para o outro como resultado da diferença de temperatura. A transferência de energia cessa quando os dois meios, de maior e menor temperatura, atingem a mesma temperatura. O calor pode ser transferido por condução, convecção e radiação. Condução é a transferência de energia das partículas mais energéticas de uma substância para partículas vizinhas adjacentes menos energéticas, como resultado da interação entre elas, podendo ocorrer em sólidos, líquidos e gases [20].

Segundo HARRIES e HARRIES [21], as fibras por si só, não são quentes nem frias, sendo a estrutura do fio ou do tecido que determina em grande parte a condutividade ou retenção térmica do tecido. $\mathrm{O}$ calor provém do corpo e se as fibras forem estruturadas de modo que o calor possa escapar, o tecido resultante terá alta condutividade térmica. Caso contrário, um tecido que não permite que o calor seja removido do corpo resultará em retenção térmica e sensação de calor pelo usuário [21].

FERREIRA [22] define condutividade térmica como a taxa de calor transferido através de um material com espessura determinada, por unidade de tempo. A composição química, estado físico, textura e temperatura do material são fatores que influenciam na condutividade térmica [22]. Quanto maior a condutividade de um material, mais este permite a transferência de calor [15]. Neste sentido, o resultado do ensaio de condutividade térmica (tabela 6) mostra que o TR tem cerca de 16\% menos condutividade, o que significa que ele irá reter mais o calor, o que está de acordo com o teste de permeabilidade.

Tabela 6: Peso dos tecidos.

\begin{tabular}{c|c|c}
\hline \multicolumn{3}{c}{ Condutividade Térmica (W/mK) } \\
\hline Amostras & Reciclado & Não reciclado \\
\hline 1 & 0,067 & 0,080 \\
\hline 2 & 0,072 & 0,080 \\
\hline 3 & 0,062 & 0,080 \\
\hline Média & $\mathbf{0 , 0 6 7}$ & $\mathbf{0 , 0 8 0}$ \\
\hline
\end{tabular}

Nesse caso, o TR pode ser mais indicado para situações onde o corpo está mais perto do repouso (figura 7) em situações de temperaturas ambiente mais baixas. Já o TNR, por ter uma condutividade mais alta, seria 
SCHMITT , J.L.; FOLLE, L.F.. revista Matéria, v.26, n.1, 2020.

mais indicado para atividades metabólicas de mais intensidade e onde a temperatura ambiente fosse mais alta. Esse resultado está de acordo com os dados obtidos acima, uma vez que o fio do TR apresenta uma espessura maior sob o mesmo tipo de ligamento, consequentemente, ele irá apresentar uma maior retenção de calor.

ÇENGEL [20] explica que a taxa metabólica pode ser interpretada como a taxa de consumo de energia do corpo. A taxa metabólica basal de um homem médio $(30$ anos, $70 \mathrm{~kg}, 1,73 \mathrm{~m}$ de altura, 1,8 m² de superfície) é de $84 \mathrm{~W}$, ou seja, o corpo converte a energia química dos alimentos em calor a uma taxa de $84 \mathrm{~J} / \mathrm{s}$, que depois é dissipada para o meio envolvente [20]. As taxas metabólicas durante várias atividades por unidade de superfície corporal são descritas na figura 7.

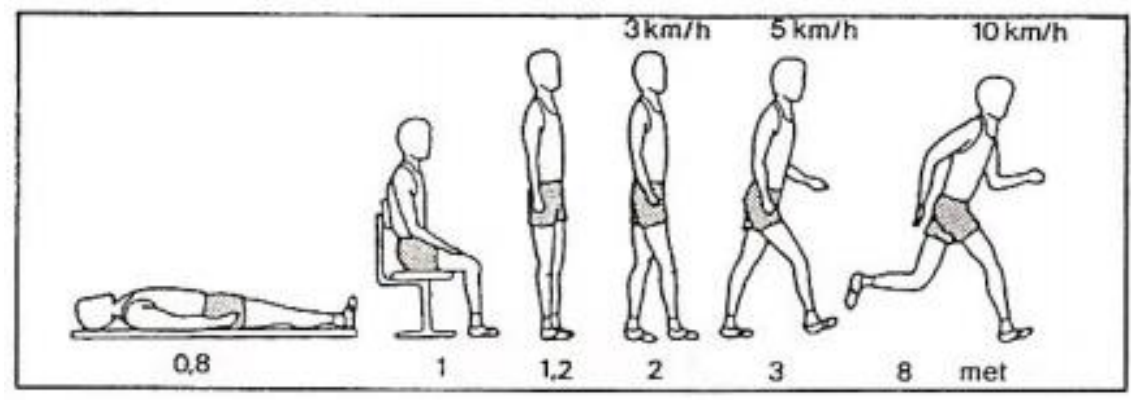

Figura 7: Níveis de atividade física e taxas metabólicas. Fonte: Çengel (2012)

\subsection{Resistência à tração}

O ensaio de tração é um experimento mecânico, que consiste na aplicação de carga de tração uniaxial crescente em um corpo de prova específico até sua ruptura [23]. Segundo DALCIN [24], este ensaio é amplamente utilizado na indústria de componentes mecânicos, pela vantagem de fornecer dados quantitativos das características mecânicas dos materiais. FERDOUS et al [25] consideram que a resistência à tração é um dos aspectos mais importantes para caracterizar a excelência e a performance de um tecido.

Os ensaios de tração iniciaram com os corpos de prova do TR seguido pelos corpos de prova do TNR. Foram ensaiadas três amostras em cada sentido dos tecidos e seus resultados foram organizados em formas de gráficos, utilizando a curva média como referência, com variáveis força $(\mathrm{N})$ e deslocamento $(\mathrm{mm})$. Desta forma, a figura 8 mostra os corpos de prova ensaiados nos três sentidos: trama, urdume e viés.

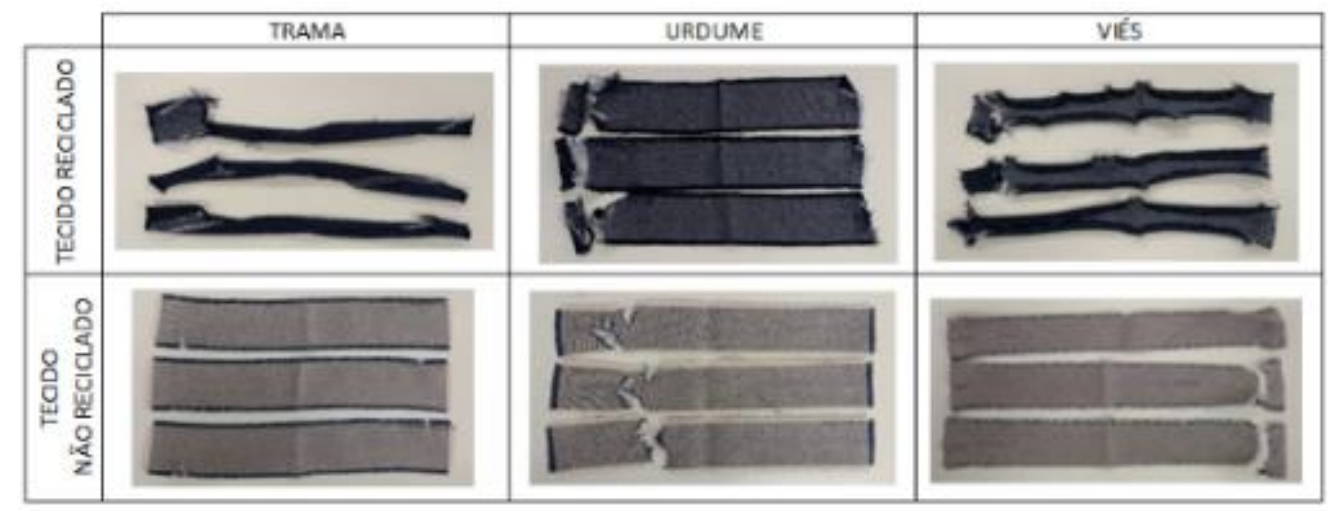

Figura 8: Corpos de prova ensaiados no teste de tração.

A primeira observação da figura 8 está relacionada ao aspecto final das amostras após serem submetidas aos ensaios de tração. Identifica-se que o TR ficou com as bordas torcidas nos sentidos da trama e do viés, não retornando ao seu estado inicial após a conclusão do ensaio. Acredita-se que a provável causa desta torção está relacionada ao fio do tecido reciclado ter passado pelo processo de torção duas vezes, uma na produção do tecido virgem e a outra na produção do tecido reciclado, gerando um acúmulo de torção que ao ser tracionado, gera um retorno em formato enrolado do tecido.

Outra suposição está relacionada a pressão que o corpo irá exercer sobre o tecido durante o uso. Nos lugares onde o corpo promover pressão e alongamento do tecido, poderá ocorrer essa torção. Segundo THEI- 
SCHMITT , J.L.; FOLLE, L.F.. revista Matéria, v.26, n.1, 2020.

SEN [26], as regiões corporais onde a roupa exerce maior pressão está localizada na coxa, cintura e joelho. Assim, o aspecto visual e estético da peça, poderá ser prejudicado e exibir torções já no primeiro uso.

Na figura 9 foram apresentados os resultados dos ensaios nas três direções, referente ao TR, em que a força $(\mathrm{N})$ foi aplicada até o rompimento. É possível observar que o sentido do urdume foi o que apresentou menor resistência, seguido pelo viés e trama, porém com pouca variação. Esperava-se como resultado que o sentido do urdume apresentasse maior resistência, no entanto, como já foi mencionado, o TR tem uma fibra de comprimento menor, e igualmente menor entrelaçada no fio, fazendo com que o tecido tenha perdido resistência nessa direção.

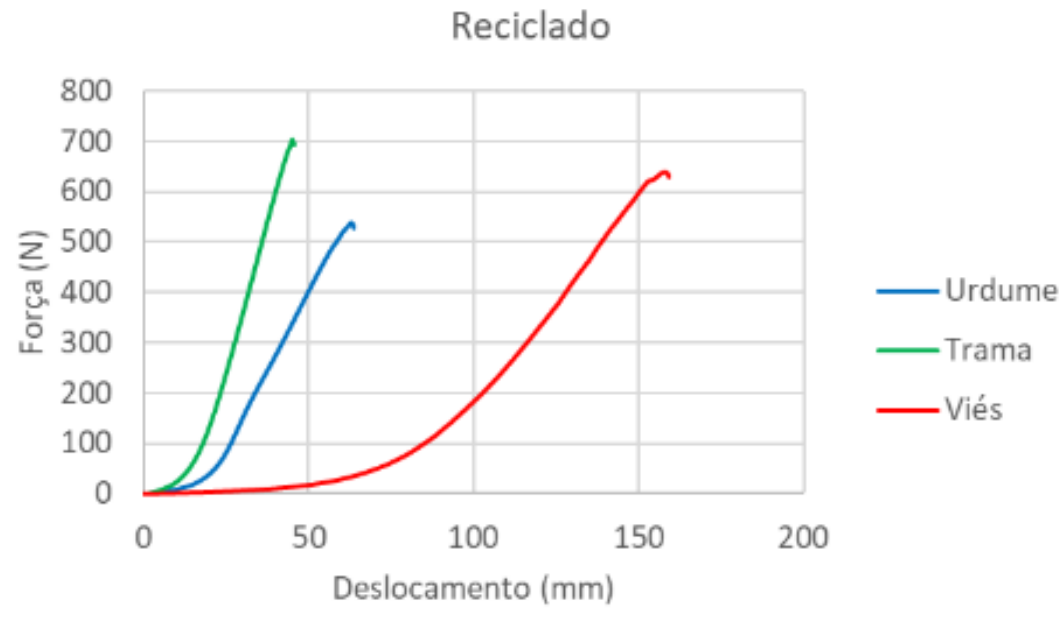

Figura 9: Resultado do ensaio de tração no tecido reciclado

Na figura 10, percebe-se uma diferença considerável em relação a força $(\mathrm{N})$ aplicada até o momento da ruptura nos três sentidos. O corpo de prova no sentido da trama rompeu-se com menor força (aprox. 800N) e obteve o menor deslocamento, sendo que no sentido do urdume foi necessária uma força superior à $1300 \mathrm{~N}$ para o rompimento da amostra.

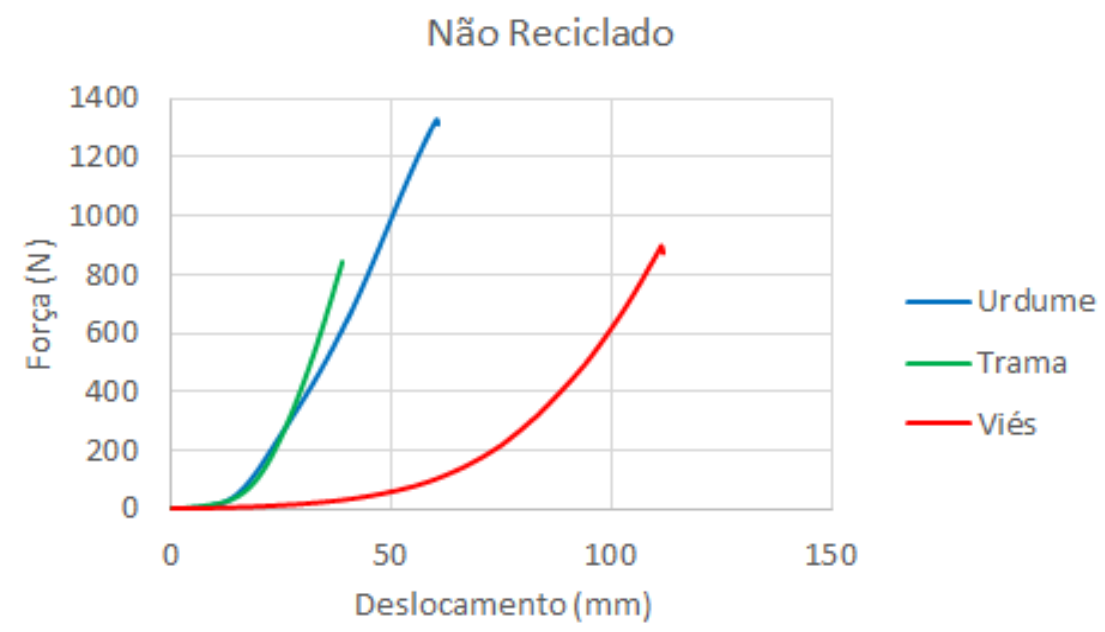

Figura 10: Resultado do ensaio de tração no tecido não reciclado.

Para melhor comparar os resultados, foi plotado o gráfico da figura 11, que apresenta os dois tecidos nos três sentidos. Nele, é possível notar que o TR só apresenta maior resistência que o TNR na trama, sendo que no urdume, a resistência é mais que o dobro do TNR em relação ao TR. Outra observação importante é que o alongamento do TR, tanto na urdume quanto no viés é maior que no TNR. Isso indica que o TR poderá ter um conforto ergonômico maior que o TNR, uma vez que seria preciso menor força para fazer o TR alon- 


\section{Tração nos Tecidos}

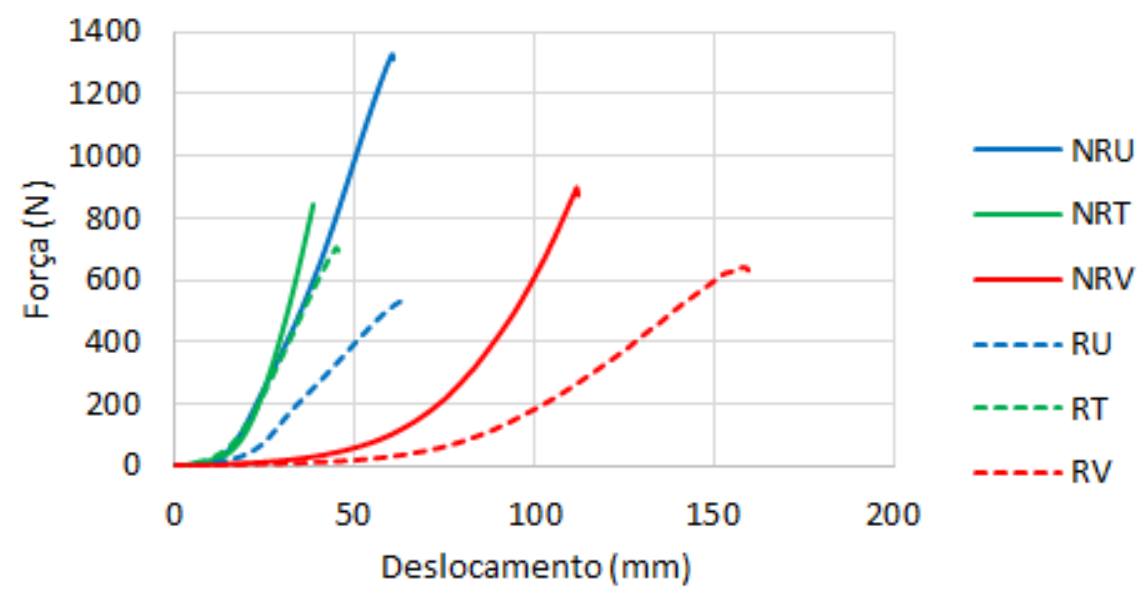

Figura 11: Comparativo entre os gráficos.

Buscando agregar mais informações e obter mais dados sobre o desempenho dos tecidos, optou-se por realizar ensaios de tração com fios dos tecidos reciclados e não reciclados (figura 12). Foram retiradas por desfiamento, três amostras de fios no sentido da trama e urdume. As amostras foram condicionadas à temperatura ambiente e suas extremidades foram enroladas nas garras para evitar o deslizamento do fio durante à tração.

A partir da análise de resistência à tração dos fios foi possível identificar que o fio de trama do algodão não reciclado apresentou o melhor desempenho de resistência, rompendo com quase o dobro de carga aplicada no fio desempenho inferior, no caso o poliéster reciclado.

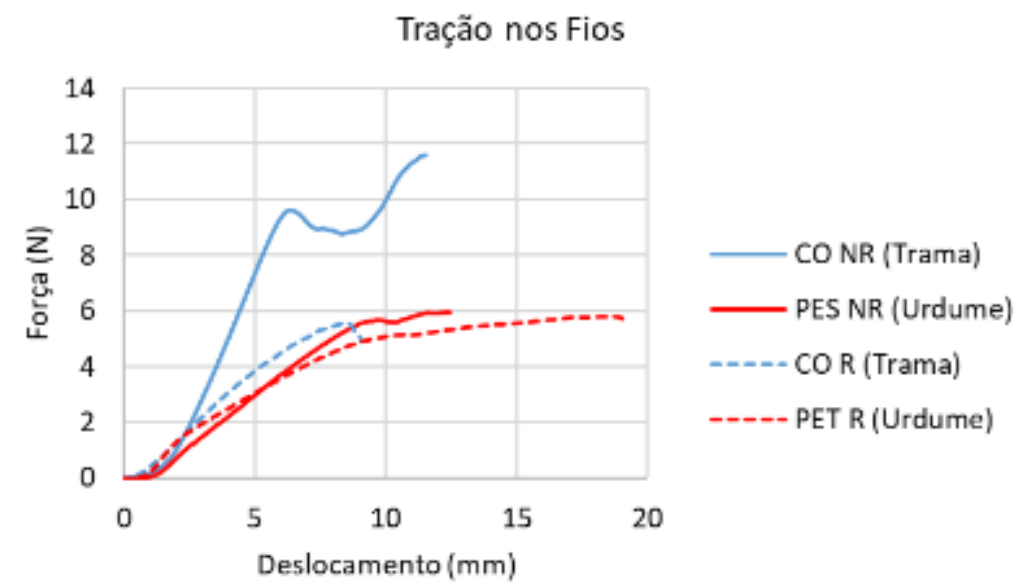

Figura 12: Ensaio de tração com fios.

Para melhorar a visualização dos resultados de resistência do tecido, a tabela 7 mostra um resumo das características de tração dos fios em comparação com o tecido. É possível observar que a fibra mais curta do algodão reciclado faz com que o fio tenha que ser mais espesso, ou seja com maior titulação, par que não haja perdas de resistência do tecido na direção do fio de algodão. O fio reciclado tem a metade da resistência do fio não reciclado o que faz com que o número de fios tenha que ser maior (40\%) para ter a resistência próxima ao não reciclado. No entanto, com mais fios de algodão, é necessário colocar menor fios de PET para que o tecido não fique muito espesso, o que faz com que resistência seja menos da metade do não reciclado no sentido do urdume. É importante notar que a titulação do fio reciclado de PET é praticamente a metade que o 
SCHMITT , J.L.; FOLLE, L.F.. revista Matéria, v.26, n.1, 2020.

fio não reciclado com a mesma resistência, no entanto a elasticidade é cerca de $45 \%$ maior.

Tabela 7: Resumo das propriedades dos tecidos e dos fios.

\begin{tabular}{l|c|c|c|c}
\hline & CO TR & CO TNR & PET TR & PES TNR \\
\hline Tração do tecido & $700 \mathrm{~N}$ & $800 \mathrm{~N}$ & $550 \mathrm{~N}$ & $1300 \mathrm{~N}$ \\
\hline Tração do fio & $6 \mathrm{~N}$ & $12 \mathrm{~N}$ & $6 \mathrm{~N}$ & $6 \mathrm{~N}$ \\
\hline Titulação & $85,1 \mathrm{TEX}$ & $68,1 \mathrm{TEX}$ & $16,7 \mathrm{TEX}$ & $32,1 \mathrm{TEX}$ \\
\hline $\mathrm{N}^{\circ}$ de fios por cm & 28 & 20 & 21 & 44 \\
\hline
\end{tabular}

Observando a tabela 7, fica evidente a estratégia adotada pelas indústrias de fabricação de tecidos reciclados para não perder em resistência e leveza do tecido. No entanto é preciso se ter mais estudos sobre o assunto para viabilizar maiores usos dos tecidos reciclados e que esses possam ser inseridos no contexto das vendas ao consumidor final.

\section{CONCLUSÕES}

Com base nos resultados dos ensaios realizados, foi possível concluir que ambos os tecidos tiveram desempenhos semelhantes nos ensaios de gramatura e permeabilidade. No entanto, apresentaram diferenças na condutividade térmica e no ensaio de tração.

Conforme visualizado na micrografia, os fios de algodão dos tecidos reciclados apresentaram fibrilas no seu contorno. Pressupõe-se que esse comportamento da fibra é ocasionado devido à redução média de $20 \%$ no comprimento da fibra após o processo de desfibragem do tecido. Essas fibrilas em volta do fio de algodão interferem na condutividade térmica, fazendo com que o tecido reciclado segure mais o calor no interior da roupa e, consequentemente seja considerado um tecido com melhor desempenho térmico se usado no inverno. Em contrapartida, o TNR é um tecido que apresenta um bom desempenho térmico para roupas de verão, já que os espaços vazios entre os fios permitem que o vapor de água ultrapasse o tecido juntamente com o calor.

Quanto ao ensaio de tração, identificou-se que o TNR no sentido do urdume apresenta boa resistência, em contrapartida com o TNR no sentido da trama, apresentou resistência inferior, podendo romper-se com facilidade nos pontos de maior pressão.

É importante observar que, os dados obtidos referem-se às amostras adquiridas para esta pesquisa, sendo que uma generalização para qualquer tecido reciclado, deve ser avaliado para várias amostras de fabricantes diferentes. No entanto, alguns indícios aqui levantados podem fazer com que a aplicação desse tipo de tecido seja melhor feita com base nas suas propriedades. Por exemplo, se o tecido demostrou que sofre torções ao ser submetido a uma carga, porem apresenta maior alongamento e maior retenção de calor, um uso mais adequado seria em tecido de preenchimento interno de casacos.

Os dados aqui levantados são importantes para gerar informações relevante tanto para a indústria da reciclagem, quanto para a indústria da moda, pois poderão gerar um consumo mais consciente juntamente com um uso mais adequado de acordo com a resposta que a matéria fornece após o uso. Outro ponto a ser importante a ser destacado aqui é que o usuário final deve, ao longo das pesquisas participar das mesmas para que o que foi levantado através de experimentos seja confirmado no uso final.

\section{BIBLIOGRAFIA}

[1] TREPTOW, D. Inventando moda: planejamento de coleção. 5. ed. São Paulo: Edição do autor, 2013.

[2] ABIT - ASSOCIAÇÃO BRASILEIRA DA INDÚSTRIA TÊXTIL E DE CONFECÇÃO. Disponível em: http://www.abit.org.br/home. Acesso em: 10 jun. 2017.

[3] BERLIM, L. Moda e sustentabilidade: uma reflexão necessária. São Paulo: Estação das Letras e Cores, 2014.

[4] CARVAlHAL, A. Moda com propósito. São Paulo: Companhia das Letras, 2016.

[5] LEE, M. Eco chic: o guia de moda ética para a consumidora consciente. São Paulo: Larousse, 2009.

[6] LASCHUK, T. Design têxtil: da estrutura à superfície. Porto Alegre: UniRitter, 2009.

[7] CHATAIGNIER, G. Fio a fio: tecidos, moda e linguagem. São Paulo: Estação das Letras, 2006. 
SCHMITT , J.L.; FOLLE, L.F.. revista Matéria, v.26, n.1, 2020.

[8] ARAÚJO, M.; CASTRO, E. M., Manual de engenharia têxtil. Lisboa: Fundação Calouste Gulbenkian, Vol 2. 1987.

[9] ASSOCIAÇÃO BRASILEIRA DE NORMAS TÉCNICAS. Rio de Janeiro. NBR 13214:1994 Materiais têxteis - Determinação do título de fios.

[10] ASSOCIAÇÃO BRASILEIRA DE NORMAS TÉCNICAS. Rio de Janeiro. NBR 8427: 2015 Emprego do sistema tex para expressar títulos têxteis - Procedimento.

[11] ASSOCIAÇÃO BRASILEIRA DE NORMAS TÉCNICAS. Rio de Janeiro. NBR 8428: 2015 Condicionamento de materiais têxteis para ensaios - Procedimento.

[12] ASSOCIAÇÃO BRASILEIRA DE NORMAS TÉCNICAS. Rio de Janeiro. NBR 10591:2008 Materiais têxteis - Determinação da gramatura de superfícies têxteis.

[13] ASSOCIAÇÃO BRASILEIRA DE NORMAS TÉCNICAS. Rio de Janeiro. NBR 12834:2005 Couros Determinação da Permeabilidade ao vapor de água.

[14] ASSOCIAÇÃO BRASILEIRA DE NORMAS TÉCNICAS. Rio de Janeiro. NBR 10455: 2014 Climatização de materiais usados na fabricação de calçados e correlatos

[15] C-THERM. Disponível em: https://ctherm.com/products/thermal_conductivity_testing/. Acesso em: 25 nov. 2018.

[16] ASSOCIAÇÃO BRASILEIRA DE NORMAS TÉCNICAS. Rio de Janeiro. NBR 11912: 2016 Materiais têxteis - Determinação da resistência à tração e alongamento de tecidos planos (tira) em dinamômetro tipo CRT.

[17] ZONATTI, W. F. Geração de resíduos sólidos da indústria brasileira têxtil e de confecção: materiais e processos para reuso e reciclagem. Tese (Doutorado em Sustentabilidade) - Escola de Artes, Ciências e Humanidades da Universidade de São Paulo, São Paulo, 2016.

[18] BORELLI, C. Comparativo das propriedades de transporte de umidade, capilaridade, permeabilidade ao vapor e permeabilidade ao ar em tecidos planos de poliéster. Tese (Doutorado em Engenharia Química) Programa de pós-graduação em Engenharia Química, Faculdade de Engenharia Química, Universidade Estadual de Campinas, Campinas, 2013

[19] GASI, F. Estudo das propriedades de conforto em tecidos de malha das fibras de poliéster e poliamida 6.6: permeabilidade ao vapor, transporte de umidade e proteção ultravioleta. Disponível em:

<http://texcontrol.com.br/wp-content/uploads/2016/02/Propriedades-de-conforto-em-tecidos-de-malha-senaitrajes-de-protecao.pdf> Acesso em: 01 jun. 2018.

[20] ÇENGEL, Yunus A. Transferência de calor e massa: uma abordagem prática. 3. ed. São Paulo, SP: Mc Graw Hill, 2009.

[21] HARRIES, N. G.; HARRIES, T. E. Materiais têxteis: curso técnico programado. São Paulo: EPU., v.1. 1976.

[22] FERREIRA, P. M. C. Evolução da temperatura em elementos de aço sujeitos ao fogo. Dissertação (Mestrado em Engenharia Civil) - Faculdade de Ciências e Tecnologia, Universidade nova de Lisboa, Lisboa, 2011.

[23] GARCIA, A.; SPIM, J. A.; SANTOS, C. A. Ensaios dos materiais. 2.ed. Rio de Janeiro: LTC, 2012.

[24] DALCIN, G.B. Ensaios dos Materiais. Curso Engenharia Industrial Mecânica, URI - Universidade Regional Integrada do Alto Uruguai e das Missões, Santo Ângelo, Rio Grande do Sul, Brasil, 2007.

[25] FERDOUS, N.; RAHMAN, S.; KABIR, R. A. "Comparative study on tensile strength of different wave structures”. International journal of scientific research engineer \& technology, v. 3, n. 9, pp. 1307-1313, 2014.

[26] THEISEN, Fernanda C. Calça Jeans Feminina: Influência da pressão na sensação de conforto. Dissertação de Mestrado em Design - UniRitter. Porto Alegre. 2016

\section{ORCID}

Juliana Lunkes Schmitt https://orcid.org/0000-0001-5860-7268

Luis Fernando Folle https://orcid.org/0000-0002-3829-496X 